\title{
Solar PV Powered Energy Efficient LED Lighting System for a Class Room
}

\author{
P. Sathya ${ }^{1, *}$ and R. Natarajan ${ }^{2}$ \\ ${ }^{1}$ School of Electronics Engineering, VIT University, Vellore - 632 014, Tamil nadu, India. \\ ${ }^{2} \mathrm{CO}_{2}$ Research and Green Technologies Center, VIT University, Vellore - 632 014, Tamil nadu, India
}

Received 6 September 2014; Accepted 1 October 2014

\begin{abstract}
This paper presents the design of Solar PV based LED lighting system suitable for a class room. The model of class room is created using DIALux 4.11and LED lighting system is provided inside the room for illumination. The design calculations of the lighting are done as per the IESNA (Illumination Engineering Society of North America) standards. Based on the lighting load requirement, the number of solar panels and batteries required to generate and store the power is determined. To assess the performance of the lighting system, simulation is done and the photometric parameters are calculated from the observed values. In addition to the photometric parameters, the annual lighting energy required for illuminating the room is also estimated. The computed result has proved that the LED lighting system is suitable for residential indoor applications providing good visual clarity and comfort.
\end{abstract}

Keywords: Luminous efficacy, Uniformity of illuminance, Glare index, Luminance, color rendering index (CRI).

\section{Introduction}

Lighting plays a vital role in regular human activities which is naturally available from the sun in day time. To carry out the human activities throughout artificial lighting is required. Such an artificial lighting should be as close as possible in replicating the natural lighting. It should be environmentally and functionally suitable for people working inside the task area. On the other hand, lighting is the major consumer of electrical energy accounting for around $21 \%$ of the world's total electricity production. Reducing the electrical energy consumption by using energy efficient lamps is an important solution for this problem. Additionally, the power can also be generated from renewable energy such as solar, wind and biomass. Power generation from such renewable sources especially solar, offers better energy management for current situation. Many research works has been carried out in the past few years to generate power from solar and also to maximize its energy conversion efficiency. Meeting the energy demand and using the available power in a judicious way is the solution for energy crisis prevailing now.

The invention of LED lights is greatly helpful in reducing the power consumption. Many research studies have been done on LED to implement in indoor and outdoor lighting applications. An intelligent LED lighting system that automatically adjust the minimum light intensity value to enhance both energy efficiency and user satisfaction has been developed resulting in $21.9 \%$ reduction in power consumption [1]. The power consumptions and efficiency of traditional lights sources and LED lights in illuminating the household environment were analyzed and compared with

\footnotetext{
*E-mail address: p.sathya@vit.ac.in

ISSN: 1791-2377 (C) 2014 Kavala Institute of Technology. All rights reserved.
}

each other at average standard illuminance. This has proved that LED lighting consumes less power producing high efficiency [2]. Performance of the different light sources was tested based on power quality measurements. The result has proved that LED lights have poor factor and correction has to be done. Lighting design for an indoor task environment should result in good visual comfort, visual performance and energy efficiency [4]. An experimental setup of PV based WLED lighting system for indoor application has been verified which resulted in $96 \%$ driver efficiency and light output of 329-370 1x inside the room [5]. Several lighting control algorithms and software techniques are available, which enables us to model and pre-visualize the lighting condition [6]. This would be helpful for the lighting designers and researchers to decide on the illumination condition for a specified task area.

The objective of this paper is to design a solar PV powered lighting system for a class room that should be functionally suitable for the group of people working inside. It should be aesthetically pleasant, visually comfortable and consume less power. It should have a good energy balance between power generation and power consumption. Here a class room model is created along with LED lighting system in Dialux and simulated to pre-visualize the illumination condition [7]. LED lamp is used here because the rated lifetime of this lamp ranges from $35000-50000$ hours, with an average luminous efficacy of $641 \mathrm{~m} / \mathrm{W}$ [8]. The CRI is around 93 and CCT is around (2700-3000) K. The LED lamp used in this project is obtained from the Philips plug in module [9]. The rest of the paper is organized as follows. Section 2 describes the design of class room model with lighting system. Section 3 explains the methodology for implementing solar PV modules for power generation. Section 4 presents the simulation results of the lighting 
system. The quantitative and qualitative parameters of lighting are determined and analyzed. Energy required for lighting the room throughout a year is also estimated in this section based on European standard [10].

\section{Design of Class Room and Lighting System}

A model of class room is designed using the lighting software DIALux 4.11 version. The specifications of the room are length $(1)=8 \mathrm{~m}$, width $(\mathrm{b})=6 \mathrm{~m}$ and height $(\mathrm{h})=$ $3 \mathrm{~m}$. This is a rectangular room with a wooden door of reflectivity, $\rho_{\text {door }}=0.55$ on one side. Two long sides of the room is embedded with a pair of windows having reflectivity $\rho_{\text {window }}=0.5$. The reflectivity of room elements are $\rho_{\text {wall }}=0.51, \rho_{\text {ceiling }}=0.8$ and $\rho_{\text {wall }}=0.20$. The measurements are taken from a work-plane at a height of $0.8 \mathrm{~m}$ from the floor. Inside the room 25 chairs and a marker board are placed. The $3 \mathrm{D}$ view of class room model and the floor plan made using CAD is shown in figure 1 and 2 .

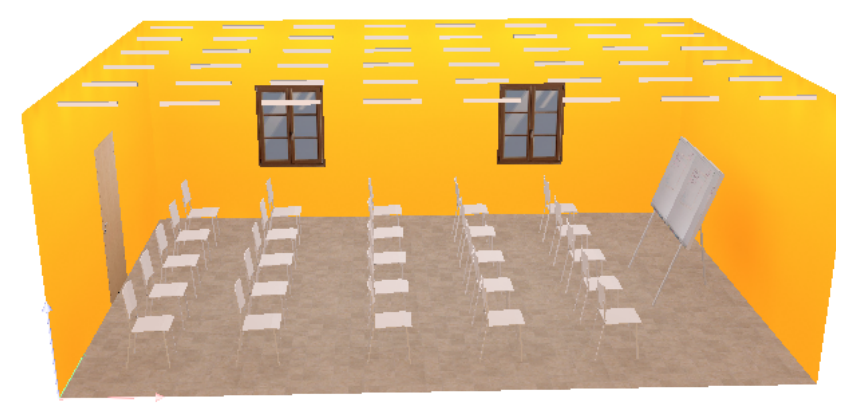

Fig. 1. Design of Class room model in DIALux 4.11

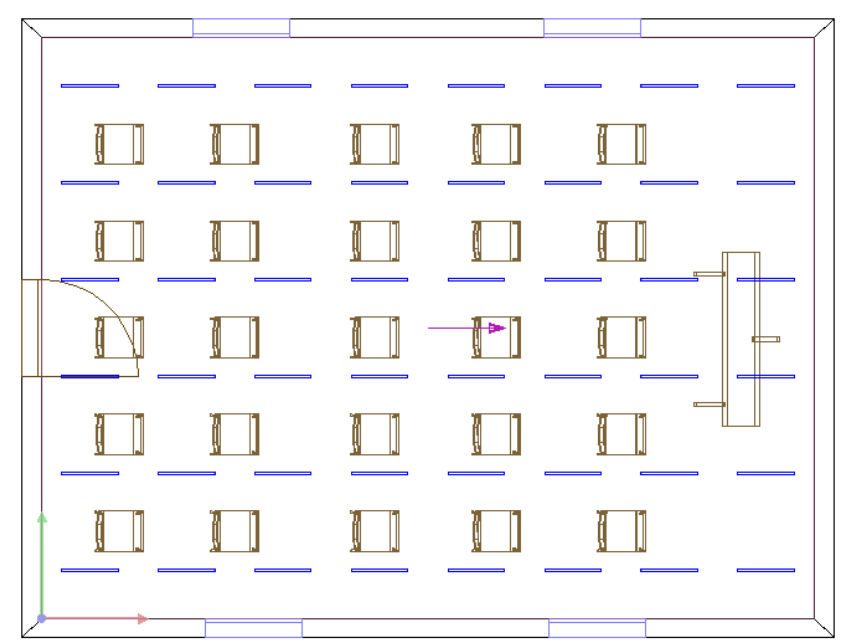

Fig. 2. Floor plan view of Class room model in DIALux 4.11

\subsection{Lighting system design}

Lighting systems are effectively designed based on the IESNA (Illuminating Engineering Society of North America) standard to perform task inside the class room. It has published lighting hand book that contains recommended data sheet for lighting. Lighting depends on various factors such as purpose intended service, class of interiors, luminaire best suited, color effect and reflection from floor, ceiling and walls. The basic requirements of lighting system to be furnished in class room are listed below.
1. Intensity should be ample for clear and distinct vision

2. Uniform distribution of brightness within the space

3. Appropriate horizontal and vertical lighting value

4. Suitable color of the light source

5. Reduction of glare

6. Location of light source well above the range of vision.

As per the IESNA standard, the required illuminance level for the class room should be $3001 \mathrm{x}$ measured at $0.8 \mathrm{~m}$ from the floor. The range of glare limiting index should be 19 and the color rendering index should be more than 80 .

Initially the task at functional level is to determine number of luminaries required and suitable way to place them for correct level of illumination for a given activity. Total flux method is used here to compute the number of luminaries required for illumination and placement of luminaries are done according to field pattern arrangement. The step wise procedure is listed below.

1. Selection of illumination level inside the room as prescribed by the IESNA standard. For a nominal class room required illumination level (E) is 300 $1 \mathrm{x}$.

2. Selection of luminaire type: Philips BN130C L584 1x LED6S/830, $\Phi_{\text {lamp }}=683$ lumen, $P=10 \mathrm{~W}$.

3. Computation of Room index:

$$
\begin{aligned}
R I & =\frac{l \times b}{(l+b) \times h_{m}} \\
& =\frac{8 \times 6}{(8+6) \times 2.2} \\
& =1.558
\end{aligned}
$$

4. Determination of reflectance of wall, ceiling and floor.

$\rho_{\text {wall }}=0.51, \rho_{\text {ceiling }}=0.8$ and $\rho_{\text {floor }}=0.2$

5. Calculation of $\Phi_{\text {installed. }}$

$$
\begin{aligned}
\phi_{\text {installed }} & =\frac{E \times A}{M F \times U F} \\
= & \frac{300 \times 48}{0.9 \times 0.48} \\
= & 33,333 \text { lumen }
\end{aligned}
$$

Where MF is Maintenance factor and UF is Utilization factor.

6. Calculation of number of luminaries required

$$
\begin{aligned}
N & =\frac{\phi_{\text {installed }}}{\phi_{\text {lamp }}} \\
& =\frac{33333}{683}=48.8
\end{aligned}
$$

For a particular value of room index, the utilization factor can be selected from the room index chart specified by the lamp manufacturer. Nominal value of maintenance factor lies between 0.8-0.9, here it is chosen as 0.9 . From the design calculation, it is found that approximately 49 
luminaries are required to illuminate the room for producing $300 \mathrm{~lx}$. To maintain symmetrical lighting arrangement, 48 luminaries are used in $8 \times 6$ field arrangement pattern as shown in figure 1 .

\subsection{Luminance Emittance of LED Lamp}

The lamp used here is Pentura Mini LED lamp specified as Philips BN130C L584 1x LED6S/830. It is an extremely slim battern that offers the energy saving benefits of LED technology, coupled with excellent lighting performance. It is a bright white light with color rendering index of more than $80 \%$ and correlated color temperature of $3000 \mathrm{~K}$. It works on ac voltage of $220-240 \mathrm{~V}, 50-60 \mathrm{~Hz}$ frequency resulting in an efficacy of $66 \mathrm{~lm} / \mathrm{W}$. The driver circuit is embedded inside the luminaire setup. The luminous emittance of the lamp is shown in figure 3. It shows that the light output ratio (LOR) which is a measure of downward light from luminary to light from lamp is $100 \%$. The intensity of light in the $\mathrm{C} 0-\mathrm{C} 180$ plane and $\mathrm{C} 90-\mathrm{C} 270$ plane is shown in the figure 3.

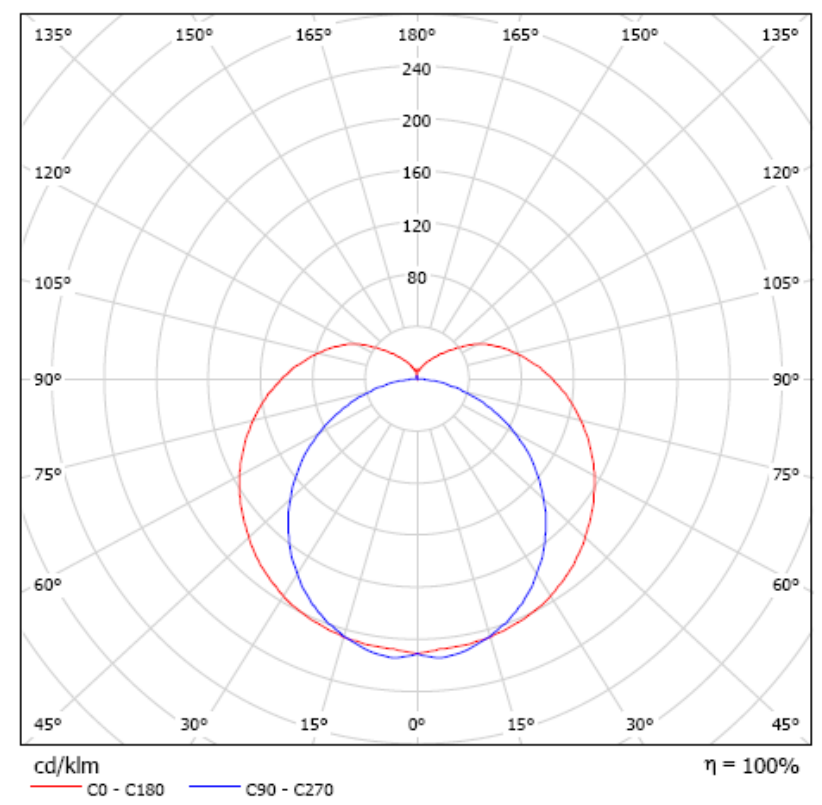

Fig. 3. Luminance emittance of Philips BN130C L584 1x LED6S/830.

\section{Design Method of Solar PV and Battery Sizing}

From the design of lighting system, the amount of power required for lighting the class room is known. To determine the number of solar photovoltaic modules, batteries and to implement them along with an inverter, the following design procedure is adopted here.

\subsection{Load estimation}

Total number of lighting load $=49$

Power rating of the lamp $=10 \mathrm{~W}$

Total power rating $=490 \mathrm{~W}$

Number of working hours $=8$ hours/day

Daily ac load demand $=3930 \mathrm{Wh}$

\subsection{Inverter Selection}

The inverter should meet all continuous loads and surge demands at any instant. So an inverter with higher dc voltage is preferred which also reduces the size of wires to be used. The selected inverter for this work has $24 \mathrm{~V} \mathrm{dc}$ input and $80 \%$ efficiency.
Maximum ac load $(A h)$

$$
=\frac{A C \text { load }(W h)}{(D C \text { input voltage } \times \text { Efficiency })}
$$

Maximum ac load $(A h)=\frac{3920 W h}{(24 V \times 0.8)}=204.16 \mathrm{Ah} / \mathrm{day}$

\subsection{Battery Sizing}

Number of days Autonomy $=3$ days

System voltage $=24 \mathrm{~V}$

Maximum battery usage (deep cycle $)=80 \%$

Temperature derate factor $(\mathrm{TDF})=0.97$

Rate factor $=1.3$

Average discharge rate $=\frac{(3 \times 24)}{0.8}=90$ hours

Selecting C/120 rate.

Battery Capacity $=\frac{\text { Autonomy } \times \text { Daily load }}{\text { Max. } \% \text { usage } \times T D F \times R F}$

Battery capacity $=\frac{3 \times 204.16}{0.8 \times 0.97 \times 1.3}=607.13 \mathrm{Ah}$

Battery selection: 12V, 180 Ah 3EL180 Exide make battery is selected for this work. Capacity of 180 Ah battery is @ $\mathrm{C} / 10$ rate.

No. of batteries in series

$$
=\frac{\text { Load nominal voltage }}{\text { Battery nominal voltage }}
$$

No. of batteries in series $=\frac{24}{12}=2$

No. of batteries in parallel $=\frac{\text { Battery capacity }}{\text { Individual Battery capacity }}(7)$

No. of batteries in parallel $=\frac{607.13 \mathrm{Ah}}{180 \mathrm{Ah}}=3.37 \cong 4$

Battery configuration: 2 series $\mathrm{x} 4$ parallel

\subsection{PVArray Sizing}

Maximum daily load $=204.16$ Ah

Module selected: Sundance Solar panel- $60 \mathrm{~W}, \mathrm{I}_{\mathrm{mp}}=3 \mathrm{~A}$

Open Circuit Voltage $\left(\mathrm{V}_{\mathrm{OC}}\right)=22.1 \mathrm{~V}$

Short Circuit current $\left(\mathrm{I}_{\mathrm{SC}}\right)=3.23 \mathrm{~A}$

Number of hours of radiation at $1000 \mathrm{~W} / \mathrm{m}^{2}=6$ hours

Module output $=6 \mathrm{~h} \times 3 \mathrm{~A}=18 \mathrm{Ah}$

$$
\text { No. of Parallel modules }=\frac{\text { Daily load demand }(A h)}{\text { Module output }(A h) \times T D F \times D F}(8)
$$

No. of Parallel modules $=\frac{204.16 A h}{18 A h \times 0.9 \times 0.9}=14$

No. of series modules

$$
=\frac{\text { Nominal system voltage }(V)}{\text { Nominal Module voltage }(V)}
$$

No.of series modules $=\frac{24 \mathrm{~V}}{12 \mathrm{~V}}=2$

Array Configuration: 2 series x 14 parallel 


\subsection{Battery sizing recheck}

The maximum rate of charge for the deep cycle battery should be at $\mathrm{C} / 5$ whereas the depth of discharge should be less than $80 \%$ for maintaining long life time of the battery.

Depth of Discharge $=\frac{\text { Daily load }(A h)}{\text { No.of parallel batteries } \times B C(A h)}$

$D O D=\frac{204.16 A h}{4 \times 180 A h} \times 100=28 \%$

Max. rate of charge $=\frac{\text { No. of parallel batteries } \times B C}{\text { No. of parallel modules } \times I_{m p}}$

Max. $R O C=\frac{4 \times 180 \mathrm{Ah}}{14 \times 3 \mathrm{~A}}=17.14$ hours

The above sizing procedure resulted in depth of discharge of $28 \%$ satisfying the discharge criteria $(<80 \%)$ and the maximum rate of charge is 17 hours which is more than 5 hours as decided by $\mathrm{C} / 5$. The layout of battery connections and solar PV arrays are shown in figure 4 and 5 respectively.

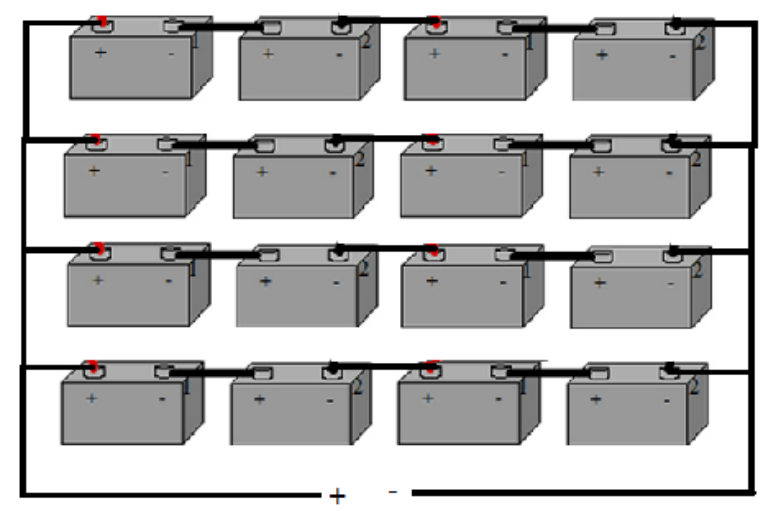

Fig. 4. Layout of battery connections $(4 \mathrm{~s} \times 4 \mathrm{p})$

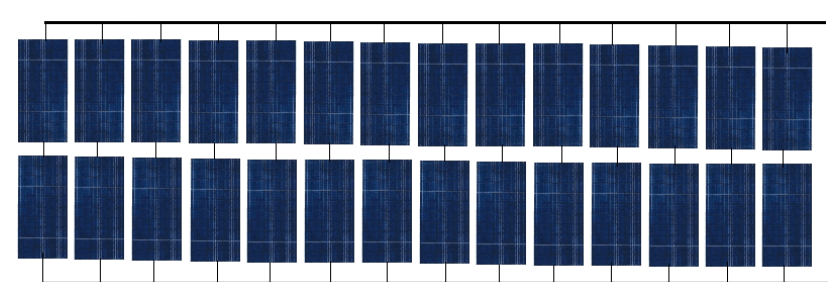

Fig. 5. Layout of Solar PV module (2s x 14p)

\section{Simulation Results}

The class room model along with the LED lighting system is simulated and 3D distribution view of light is shown in figure 6. The quantitative and qualitative parameters of lighting are measured to assess the performance of installed LED lighting system.

\subsection{Quantitative parameters}

The quantity of illumination is characterized by three parameters such as luminous flux, illuminance and luminance. The light output from the lamp is the luminous flux measured in lumen. Luminous flux of the LED lamp used here is $683 \mathrm{~lm}$. Light intensity measured on a plane at a specific location is called illuminance measured in $1 \mathrm{~m} / \mathrm{m}^{2}$ or lx. The light intensity at different locations inside the room measured at the work plane is shown in figure 7. This isoline diagram shows that illuminance at the inner area is around $420 \mathrm{~lx}$ whereas $300 \mathrm{~lx}$ near the inner periphery. Another measurement of light is luminance $\left(\mathrm{cd} / \mathrm{m}^{2}\right)$, known as brightness that measures the light leaving a surface in a particular direction. The average luminance inside the room on various surfaces is listed in table 1 .

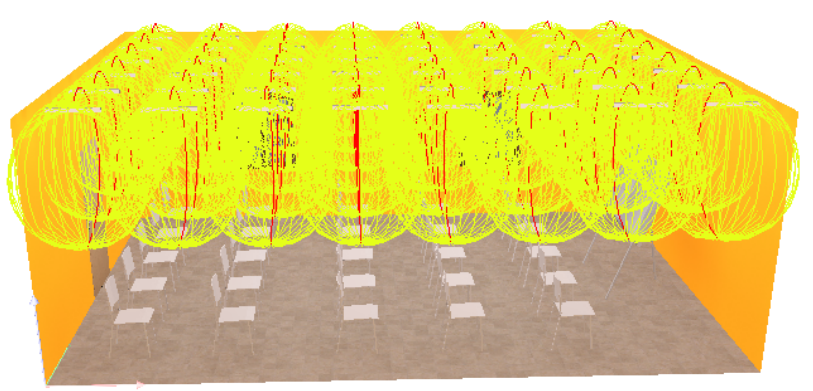

Fig. 6. 3D View of light distribution

Table 1. Photometric parameters obtained from simulation

\begin{tabular}{llllll}
\hline $\begin{array}{l}\text { Surface } \\
\mathbf{U}_{\mathbf{0}}\end{array}$ & $\boldsymbol{\rho}[\mathbf{\%}]$ & $\mathbf{E}_{\mathbf{a v}}[\mathbf{x}]$ & $\mathbf{E}_{\min }[\mathbf{I x}]$ & $\mathbf{E}_{\mathbf{m a x}}[\mathbf{x}]$ & $\mathbf{L}_{\mathbf{a v}}\left[\mathbf{c d} / \mathbf{m}^{2}\right]$ \\
\hline $\begin{array}{c}\text { Work plane } \\
0.421\end{array}$ & $/$ & 369 & 155 & 448 & $/$ \\
$\begin{array}{c}\text { Floor } \\
0.665\end{array}$ & 20 & 281 & 187 & 341 & 18 \\
$\begin{array}{c}\text { Ceiling } \\
\quad 0.476\end{array}$ & 80 & 205 & 98 & 587 & 52 \\
Walls (4) & 51 & 279 & 112 & 533 & 45 \\
\hline
\end{tabular}

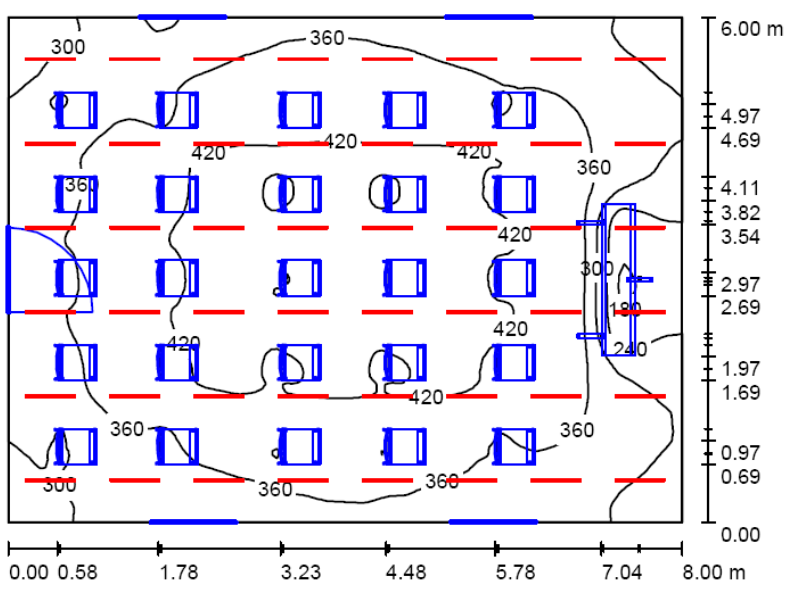

Fig. 7. Illuminance- isoline diagram

\subsection{Qualitative parameters}

There are three parameters characterizing the quality of lighting such as uniformity of illuminance, glare and color rendition. The uniformity of illuminance $\left(\mathrm{U}_{0}\right)$ is a quality issue that addresses how evenly the light spreads over a task area. It can be calculated using equation (12) shown below.

$U_{o}=\frac{E_{\min }}{E_{\text {avg }}}$

The photometric parameters obtained from the simulation are presented in table 1. From the observed illuminance values, uniformity of illuminance is calculated 
at different room surfaces. As per the IESNA standard, the recommended value of uniformity of illuminance $\left(\mathrm{U}_{0}\right)$ at the workplane should be 0.4 for normal application. Lighting system installed in the class room produces $\mathrm{U}_{0}$ of 0.421 , 0.665 and 0.476 at the workplane, floor and ceiling respectively. This confirms uniform distribution of light inside the room.

The second important quality parameter of lighting is the glare caused by luminances in the visual field that are too bright. This results in discomfort, annoyance, interference and fatigue. This glare can be reduced by not exceeding suggested light levels and by using lighting equipment designed to reduce glare. It can be quantified by the Unified Glare Rating (UGR) as shown by the following equation (13).

$$
U G R=8 \log _{10} \frac{0.25}{L_{b}} \sum \frac{\omega L_{S}^{2}}{p^{2}}
$$

Where,

$\mathrm{L}_{\mathrm{b}}$ is background luminance $\left(\mathrm{cd} / \mathrm{m}^{2}\right)$

$\mathrm{L}_{\mathrm{S}}$ is luminance of the luminaire $\left(\mathrm{cd} / \mathrm{m}^{2}\right)$

$\omega$ is the solid angle subtended at the observer's eye by the luminaire (steradians) $\mathrm{p}$ is the position index.

To determine the glare inside the room an UGR plane is fixed at a height of $0.8 \mathrm{~m}$ as shown in figure 8 . Simulation is done and the glare index at various points on the work plane is measured as shown in figure 9. The recommended value of glare index for the class room application is 19 specified by IESNA standard. From the grey scale UGR chart it is clear that value of glare index is less than 20 and is suitable for good vision.

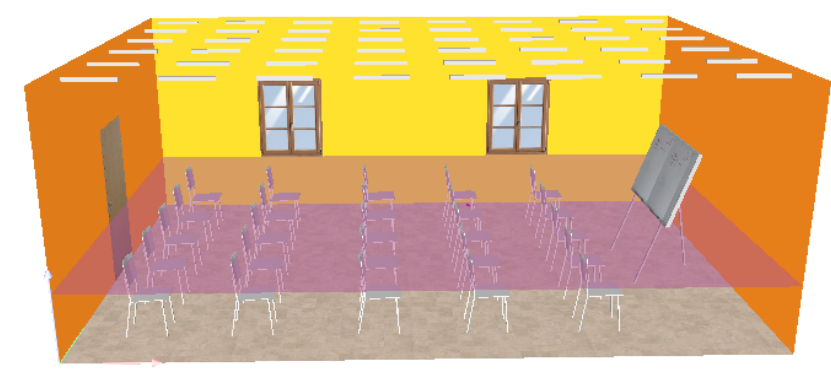

Fig. 8. UGR measurement plane inside the room

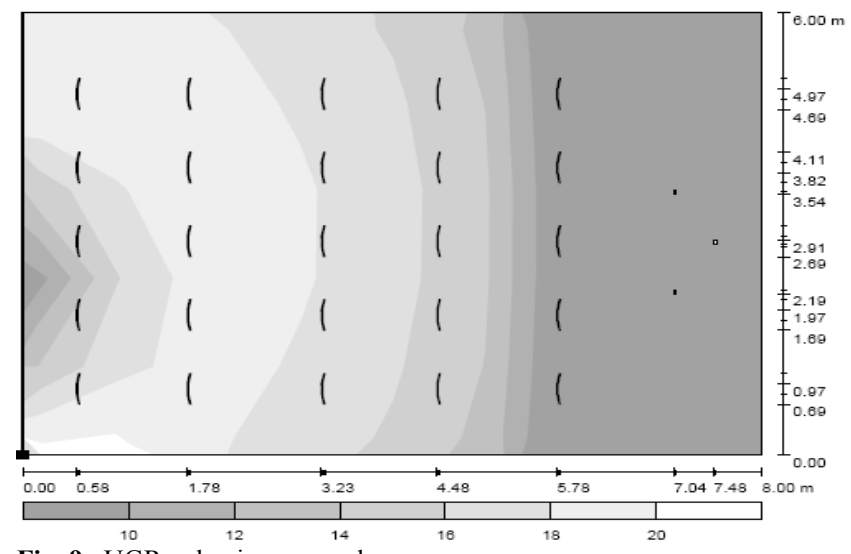

Fig. 9. UGR value in grey scale

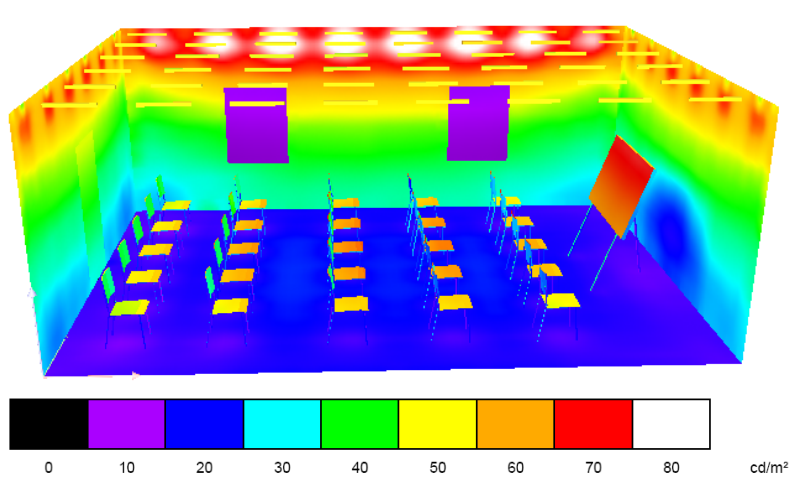

Fig. 10. False color rendering

The ability to see colors properly is another aspect of lighting quality. Light sources vary in their ability to accurately reflect the true colors of people and objects. The color rendering index (CRI) scale is used to compare the effect of a light source on the color appearance of its surroundings. A scale of 0 to 100 defines the CRI. A higher CRI means better color rendering, or less color shift. CRIs in the range of 75-100 are considered excellent, while 65-75 are good. The range of 55-65 is fair, and 0-55 is poor. Under higher CRI sources, surface colors appear brighter, improving the aesthetics of the space. The CRI of this lamp is 93 offering high quality rendering. The false color rendering of luminance values in the scale of $0-100$ is shown in figure 10.

\section{3 Evaluation of lighting energy}

The energy performance of the class room concerning the lighting requirement is calculated as per the standard EN15193. This standard uses an integral approach for the calculation of the energy balance. An energy evaluation project is created and included into the main project. It transfers the class room model along with the room elements of same properties. The surface area at the work plane of the room is divided into 2 sets of day light assessment zones (Yellow) and 3 sets of non- day light assessment zones (Violet) as shown in the figure 11. For the specific connected lighting load, energy evaluation is carried out for a complete year.

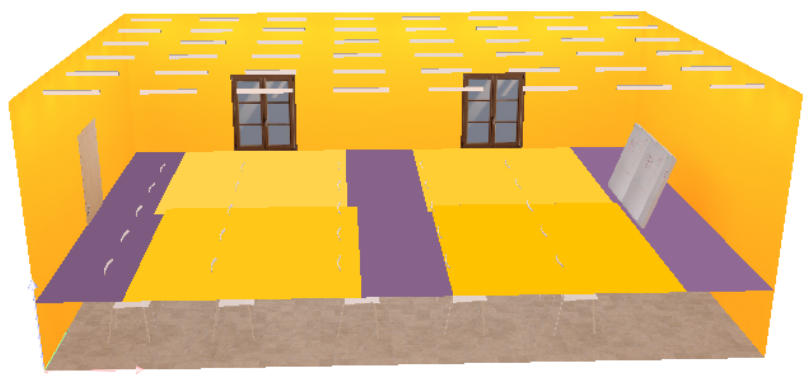

Fig. 11. Energy Assessment zones of class room

The total annual energy used for lighting and lighting energy numeric indicator (LENI) for the room can be calculated using the following equations.

$W=W_{L}+W_{P}(k W h /$ year $)$

Where $\mathrm{W}_{\mathrm{L}}$ is the illumination energy 
$\mathrm{W}_{\mathrm{P}}$ is the parasitic energy

$$
L E N I=\frac{W}{A}\left(k W h / m^{2}-\text { year }\right)
$$

Where A is the area of the room.

The total annual energy required for lighting the class room is $1001.84 \mathrm{kWh} /$ year and LENI is $20.87 \mathrm{kWh} / \mathrm{m}^{2}$ - year.

Table 2. Annual Lighting Energy consumption

\begin{tabular}{llll}
\hline $\begin{array}{l}\text { Month } \\
{\left[\mathrm{kWh} / \mathrm{m}^{2}\right]}\end{array}$ & Lighting $[\mathrm{kWh}]$ & Visual & task \\
\hline January & 87.53 & 1.82 \\
February & 85.57 & 1.78 \\
March & 83.35 & 1.74 \\
April & 81.15 & 1.69 \\
May & 79.85 & 1.66 \\
June & 79.45 & 1.66 \\
July & 80.05 & 1.67 \\
August & 80.95 & 1.69 \\
September & 82.65 & 1.72 \\
October & 84.99 & 1.77 \\
November & 88.19 & 1.84 \\
December & 88.19 & 1.84 \\
\hline
\end{tabular}

\subsection{Ray trace view}

In this experiment, radiosity method based on thermal exchange between the surfaces is used to generate real time visualization of lighting environment. The surfaces are assumed to be perfect diffusers that reflect equal amount of light in all directions as per Lamberts law. The real time view of lighting condition obtained using radiosity based simulation is shown in figure 12.

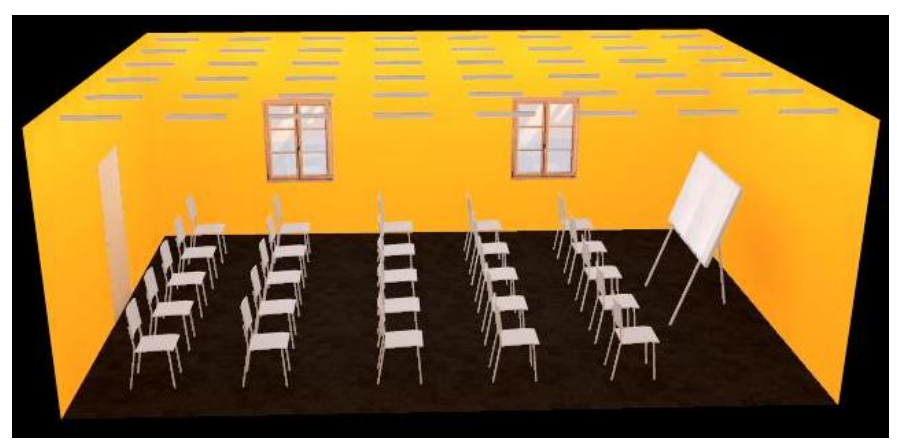

Fig. 12. Ray tracing view of real time lighting condition

\section{Conclusion}

A class room model illuminated with LED lighting system powered by solar PV module has been presented in this paper. Measured photometric parameter from the LED lighting system has proved that uniform illumination, visual comfortability and color rendering are within the specified level as mentioned by the IESNA standards. The power generation from Solar panel and power consumption by LED lighting results in better energy management when compared to conventional power generation and lighting system. Hence the solar PV powered LED lighting system is the best suited energy saving technique for indoor applications.

\section{References}

[1]. Jinsung Byun, Insung Hong, Byoungjoo Lee, and Sehyun Park, "Intelligent Household LED Lighting System Considering Energy Efficiency and User Satisfaction", IEEE Trans. Consumer Electronics, Vol.59, No.1, February 2013.

[2]. M.M.Aman, G.B.Jasmon, H.Mokhlis, A.H.A.Bakar, 2013. Analysis of the performance of domestic lighting lamps. Energy policy 52, 482- 500.Adam Tilinger, Gabor Madar, 2008. Spectral Radiosity rendering application for lighting researches. Acta Polytechnica Hungarica, Vol.5, No.3, 141-146

[3]. Wen-Shing Sun*, Chih-Hsuan Tsuei, and Yi-Han Huang, "Simulating the Illuminance and Efficiency of the LEDs used in General Houehold Lighting", Science Direct, Physics Procedia 19, 2011, pp.244-248.

[4]. Safaa ALZUBAIDI and Prashant Kumar SOORI, “ Energy Efficient Lighting system Design for Hospitals Diagnostic and Treatemnt Room - A case study”, J. Light \& Vis. Env. Vol.36, No.1, 2012.

[5]. O.S. Sastry a,n, V.KamalaDevi b, P.C.Pant a, G.Prasad a, RajeshKumar a, BibekBandyopadhyay a, " Development of white LED based PV lighting systems", Solar Energy Materials \& Solar Cells, Vol.94 (2010) pp.1430-1433.

[6]. Li Jiaa, Sina Afsharia, Sandipan Mishrab, Richard J. Radkea, “ Simulation for Pre-visualizing and tuning lighting controller behavior", Energy and Buildings, Vol. 70, 2014, pp. 287-302.

[7]. DIALux Website. Available from: $<$ http://www.dial.de/DIAL/en/dialux-internationaldownload.html> (Access on: 13 September 2012).

[8]. DoE, 2011b. LED luminaire lifetime: Recommendations for testing and reporting. Solid - State Lighting Program: U.S. Department of Energy. Availablefrom: $<$ http://apps1.eere.energy.gov/buildings/publications/pdfs/ssl/led_1 uminaire-lifetime-guide june 2011.pdf.

[9]. Philips, 2012a. Philips Product Selector 5.2.6.0.Availablefrom: http://www.lighting.philips.com/main/connect/tools_literature/dial ux_and_other_downloads.wpd
[10]. PrEN 15193, 2006: Energy Performance of buildings - energy requirements for lighting. European standard for lighting. CEN/TC 169. 